\title{
HUBUNGAN STRES PENGASUHAN DENGAN RESILIENSI ORANG TUA ANAK PENYANDANG KANKER
}

\author{
Puji Nurfauziatul Hasanah ${ }^{1}$, Fitri Haryanti ${ }^{2}$, Lely Lusmilasari ${ }^{3}$ \\ 1) Prodi Ilmu Keperawatan, Sekolah Tinggi Ilmu Kesehatan Sebelas April Sumedang \\ ${ }^{2,3)}$ Departemen Keperawatan Anak, Fakultas Kedokteran, Kesehatan Masyarakat dan \\ Keperawatan, Universitas Gadjah Mada \\ pujinurfauziatul@gmail.com
}

\begin{abstract}
ABSTRAK
Orang tua yang memiliki anak terdiagnosis kanker mengalami perubahan dalam kehidupannya. Kompleksitas rangkaian pengobatan kanker yang dihadapi mengharuskan orang tua memiliki resiliensi untuk bertahan dalam situasi krisis. Tujuan penelitian ini untuk mengetahui hubungan stres pengasuhan dengan resiliensi orang tua anak penyandang kanker di RSUP Dr. Hasan Sadikin Bandung. Penelitian ini menggunakan Rancangan Cross-sectional yang dilakukan mulai November s.d Desember 2018 terhadap 72 responden orang tua anak dengan kanker yang diambil dengan menggunakan Teknik Consecutive Sampling. Pengukuran resiliensi dinilai dengan instrumen The ConnorDavidson Resilience Scale-25INDO sedangkan stres pengasuhan dinilai dengan Parental Stress Scale versi bahasa Indonesia. Analisis data dilakukan dengan menggunakan Uji Chi-Square. Hasil penelitian menunjukkan nilai rata-rata resiliensi orang tua anak penyandang kanker sebesar 62,2. Mayoritas orang tua anak memiliki tingkat resiliensi tinggi $(55,5 \%)$. Nilai rata-rata stres pengasuhan orang tua sebesar 37,9. Tidak ada perbedaan jumlah orang tua anak penyandang kanker dengan stes pengasuhan tinggi $(50,0 \%)$ dan stres pengasuhan rendah (50,0\%). Hasil Uji Chi-Square menunjukan p-value $=0,000$ $(<0,05)$ yang bermakna ada hubungan stres pengasuhan dengan resiliensi orang tua anak penyandang kanker. Hasil penelitian menunjukan stres pengasuhan berhubungan dengan resiliensi orang tua. Faktor tersebut penting dalam perencanaan strategi intervensi dalam upaya meningkatkan resiliensi orang tua anak penyandang kanker.
\end{abstract}

Kata kunci : anak penyandang kanker, orang tua, resiliensi, stres pengasuhan

\section{Abstract}

Parents of children with cancer experienced changes in their lives. The complexity of pediatric cancer treatment requires a parent's resilience to survive in a hardship. Purpose of this study was to determine the relationship between parental stress and resilience among parents of children with cancer at Dr. Hasan Sadikin, Bandung. A cross-sectional descriptive study conducted among 72 parents of children with cancer between November 2018 and December 2018 who were selected using a consecutive sampling technique. Parents resilience assessed by Connor-Davidson Resilience Scale - 25 Questionnaire and the parental stress assessed by using Parental Stress Scale, Indonesian version. Data analysis performed with Chi-Square statistical test. Results showed that the mean value of resilience among parents of children with cancer was 62.2. The majority of parents of children with cancer has higher resilience (55.5\%). Parental stress among parents of children with cancer showed mean value 37.9. There was no difference in quantity among parents of children with cancer who had high parental stress (50.0\%) and low parental stress (50.0\%). Chi-Square statistical test shows p-value $=0.000(<0.05)$; this means there is a relationship between parental stress with resilience among parents of children 
with cancer. Our finding identified a relationship between parental stress and resilience among parent of children with cancer. This factor is essential for intervention strategies to promote resilience in parents of children with cancer.

Keyword: children with cancer, parental stress, parents, resilience

\section{PENDAHULUAN}

Kasus kanker pada anak mengalami peningkatan dan menjadi penyebab kematian utama akibat penyakit pada anak berusia $\leq 15$ tahun (Masa'deh \& Jarrah, 2017; Parker \& Hall, 2017). Kondisi kanker pada anak berdampak terhadap fisik dan psikologis yang tidak hanya dirasakan oleh anak, namun dirasakan juga oleh orang tua (Kearney et al., 2015). Ketika memiliki anak dengan kanker, orang tua memiliki kerentanan psikologis yang lebih tinggi dibandingkan dengan orang tua yang memiliki anak normal maupun yang menderita penyakit lain (Masa'deh \& Jarrah, 2017; Neu et al., 2014). Hal tersebut terjadi karena orang tua mengalami stres akibat kompleksitas penyakit kanker seperti prognosis penyakit, ketidakpastian penyakit, hospitalisasi berulang, efek samping pengobatan kanker, dan permasalahan finansial pada keluarga terkait pengobatan dan perawatan anak dengan kanker (Kohlsdorf \& Costa, 2012; Masa'Deh et al., 2013; Muscara et al., 2015; Neu et al., 2014; Norberg \& Boman, 2008). Identifikasi faktor yang potensial dalam melindungi kesehatan psikologis adalah hal yang penting bagi orang tua untuk dapat mengendalikan dampak yang ditimbulkan selama merawat anak penyandang kanker. Penelitian sebelumnya menunjukan bahwa kondisi mental yang sehat pada orang tua anak penyandang kanker dipengaruhi oleh faktor ketahanan atau resiliensi yang menjadi faktor protektif psikologis orang tua (Eilertsen et al., 2016).

Prevalensi kanker pada anak di Indonesia pada tahun 2013 mencapai 4,7\% dengan angka kematian mencapai 50-60\% (Badan Penelitian dan Pengembangan Kesehatan, 2013). Jawa
Barat merupakan salah satu provinsi yang memiliki prevalensi kanker cukup tinggi yakni sebesar 1,0\% dengan estimasi jumlah kasus terbesar ketiga di Indonesia mencapai 45.473 kasus (Badan Penelitian dan Pengembangan Kesehatan, 2013). Hasil studi pendahuluan di RCAKB pada tanggal 24-30 Januari 2018 pada 5 orang tua anak dengan kanker yang sedang menjalani pengobatan di RSUP Dr. Hasan Sadikin Bandung, seluruh orang tua mengatakan bahwa merawat anak penyandang kanker mengubah kehidupannya dan mereka merasa stres selama merawat anak.

Dalam lingkup keperawatan anak, perawat harus memiliki sensitivitas tinggi dalam menghadapi permasalahan yang dihadapi oleh orang tua ketika menjalani pengobatan kanker yang kompleks yang dijalani oleh anak penyandang kanker dan mendukung keluarga dalam menghadapi situasi sulit (Ye et al., 2015). Dukungan yang diberikan perawat dan tenaga kesehatan lain diharapkan dapat meningkatkan kesehatan mental orang tua dalam merawat anak penyandang kanker sehingga akan berdampak pada outcome kesehatan anak.

Resiliensi menjadi faktor penting dalam menghadapi situasi krisis dalam merawat anak dengan kanker. Oleh karena itu, peneliti tertarik untuk mengetahui hubungan stres pengasuhan yang dirasakan orang tua dengan resiliensi orang tua dalam merawat anak penyandang kanker. Penelitian ini diharapkan dapat bermanfaat dalam mengidentifikasi faktor risiko dan faktor strength dalam meningkatkan kesehatan psikologis orang tua menghadapi situasi krisis dalam merawat anak yang terdiagnosis kanker. 


\section{METODOLOGI}

Penelitian ini dilakukan dengan metode kuantitatif dengan Rancangan Cross sectional. Populasi pada penelitian ini adalah orang tua baik ayah atau ibu yang merawat pasien anak penyandang kanker usia 0 hingga 18 tahun yang sedang mendapatkan perawatan dan pengobatan di RSUP Dr. Hasan Sadikin Bandung pada bulan November - Desember 2018. Penelitian ini melibatkan 72 responden orang tua baik ayah maupun ibu yang merawat anak penyandang kanker yang dipilih dengan menggunakan Teknik Consecutive Sampling.

Teknik pengumpulan data dalam penelitian menggunakan data primer yang diperoleh dengan kuesioner yakni Parental Stress Scale (PSS) versi Bahasa Indonesia dan The Connor-Davidson Resilience Scale-25 (CD-RISC25 $\left.{ }^{\text {INDO }}\right)$. Kedua kuesioner tersebut telah dilakukan uji validitas dan reliabilitas oleh peneliti kepada 50 responden dengan hasil $\mathrm{r}$ hasil $>$ r tabel $(0,279)$ dan nilai Cronbach's alpha sebesar 0,858 (PSS) dan 0,887 (CD-RISC25 $5^{\mathrm{INDO}}$ ) yang menunjukkan bahwa kedua kuesioner tersebut valid dan reliabel.

Analisis data dilakukan secara univariat dan bivariat. Analisis univariat berupa distribusi frekuensidan persentase setiapvariabelsedangkan analisis bivariat dilakukan dengan Uji Statistik Chi-Square. Penelitian ini telah mendapatkan persyaratan kelayakan etik dari Komisi Etik Fakultas Kedokteran Kesehatan Masyarakat dan Keperawatan (FK-KMK) UGM pada tanggal 13 Juli 2018 dengan no Ref:KE/FK/0629/EC/2018 dan kelayakan etik dari RSUP Dr. Hasan Sadikin Bandung pada tanggal 2 November 2018 dengan nomor LB.02.01/X.2.2.2/18423/2018.

\section{HASIL}

1. Hasil Univariat

a. Gambaran Stres Pengasuhan Orang Tua
Anak Penyandang Kanker

Tabel 1. Gambaran Stres Pengasuhan (Parental Stress) dan Resiliensi Orang Tua Anak Penyandang Kanker di RSUP Dr. Hasan Sadikin Bandung Tahun $2018(n=72)$

\begin{tabular}{lcc}
\hline \multicolumn{1}{c}{ Stres Pengasuhan } & f & \% \\
\hline $\begin{array}{l}\text { Stres Tinggi } \\
(\text { skor PSS }>37,9)\end{array}$ & 36 & 50,0 \\
$\begin{array}{l}\text { Stres Rendah } \\
(\text { skor PSS } \leq 37,9)\end{array}$ & 36 & 50,0 \\
\hline
\end{tabular}

Informasi pada tabel 1 didapatkan bahwa responden memiliki nilai rata-rata stres pengasuhan sebesar 37,9 dengan skor terendah 25 dan tertinggi 54 (dari rentang skor 18-90). Hasil kategorisasi stres pengasuhan menunjukkan tidak ada perbedaan jumlah orang tua yang memiliki stres pengasuhan yang tinggi dan rendah dalam merawat anak penyandang kanker yaitu setengah responden memiliki stres pengasuhan tinggi $(50,0 \%)$ dan setengah lainnya memiliki stres pengasuhan rendah $(50,0 \%)$.

b. Gambaran Resiliensi Orang Tua Anak Penyandang Kanker

Tabel 2. Gambaran Resiliensi Orang Tua Anak Penyandang Kanker di RSUP DR Hasan Sadikin Bandung Tahun $2018(\mathrm{n}=72)$

\begin{tabular}{lcc}
\hline \multicolumn{1}{c}{ Resiliensi } & f & \% \\
\hline $\begin{array}{l}\text { Resiliensi Rendah (skor } \\
\left.\text { CDRISC-25 } 5^{\mathrm{INDO}}<62,2\right)\end{array}$ & 32 & 44,4 \\
$\begin{array}{l}\text { Resiliensi Tinggi (skor } \\
\text { CDRISC-25 }\end{array}$ & 40 & 55,5 \\
\hline
\end{tabular}

Informasi pada tabel 2 didapatkan bahwa responden memiliki nilai rata-rata skor resiliensi sebesar 62,2. Hasil kategorisasi menunjukkan sebagian besar responden memiliki resiliensi tinggi $(55,5 \%)$. 
c. Hubungan Stres Pengasuhan dengan Resiliensi Orang Tua Anak Penyandang Kanker

Tabel 3. Hubungan Stres Pengasuhan dengan Resiliensi Orang Tua Anak Penyandang Kanker di RSUP DR Hasan Sadikin Bandung Tahun $2018(n=72)$

\begin{tabular}{|c|c|c|c|c|c|c|c|c|}
\hline \multirow{3}{*}{ Stres Pengasuhan } & \multicolumn{6}{|c|}{ Resiliensi } & \multirow{3}{*}{$x^{2}$} & \multirow{3}{*}{ p-value } \\
\hline & \multicolumn{2}{|c|}{ Rendah } & \multicolumn{2}{|c|}{ Tinggi } & \multicolumn{2}{|c|}{ Jumlah } & & \\
\hline & f & $\%$ & $\mathbf{f}$ & $\%$ & $\mathbf{f}$ & $\%$ & & \\
\hline Rendah & 4 & 5,6 & 32 & 44,4 & 36 & 50,0 & \multirow{2}{*}{32,4} & \multirow{2}{*}{0,000} \\
\hline Tinggi & 28 & 38,9 & 8 & 11,1 & 36 & 50,0 & & \\
\hline Total & 32 & 44,5 & 40 & 55,5 & 72 & 100 & & \\
\hline
\end{tabular}

Informasi pada tabel 3 menunjukkan hasil tabulasi silang antara stres pengasuhan dengan resiliensi orang tua anak penyandang kanker. Dari tabel tersebut didapatkan bahwa sebagian besar orang tua yang memiliki stres pengasuhan tinggi, memiliki tingkat resiliensi yang rendah $(38,9 \%)$ dan orang tua yang memiliki stres pengasuhan rendah memiliki tingkat resiliensi yang tinggi $(44,4 \%)$. Hasil Uji Statistik Chi Square menunjukkan nilai $\mathrm{X}^{2}$ hitung $=32,4>$ $\mathrm{X}^{2}$ tabel $=3,841$ dan $p$-value sebesar $0,000<\alpha$ $=0,05$, yang berarti bahwa ada hubungan stres pengasuhan dengan tingkat resiliensi orang tua yang merawat anak penyandang kanker yang sedang melakukan perawatan dan pengobatan di RSUP DR Hasan Sadikin Bandung pada bulan November - Desember tahun 2018.

\section{PEMBAHASAN}

Hasil penelitian ini menunjukkan bahwa nilai rata-rata resiliensi orang tua dalam merawat anak penyandang kanker adalah $62,2 \pm 10,1$ dari rentang total $0-100$ dengan skor minimum dan maksimum yang diperoleh adalah 41 dan 89 . Hasil kategorisasi jenjang menunjukkan sebagian besar orang tua memiliki tingkat resiliensi tinggi sebanyak 55,6\%. Persentase ini tidak berbedajauh dengan orang tua dengan resiliensi rendah yakni sebesar 44,4\%. Hasil penelitian ini didukung oleh penelitian serupa di India yang dilakukan oleh Habibpour et al., (2019) dan Ye et al., (2015 $\&$ 2017) di China dengan menggunakan alat ukur serupa (CD-RISC25). Penelitian sebelumnya yang dilakukan oleh Habibpour et al., (2019) di India menunjukkan resiliensi orang tua anak penyandang kanker memiliki tingkat resiliensi dengan rentang rendah hingga sedang dengan nilai rata-rata sebesar $66,83 \pm 14,28$. Sementara penelitian yang serupa yang dilakukan sebelumnya di China yang dilakukan oleh Ye et al., (2015) menunjukkan rata-rata resiliensi orang tua anak penyandang kanker yang lebih rendah yakni $54,86 \pm 12,88$.

Keluarga seringkali dihadapkan dengan berbagai permasalahan dalam menghadapi situasi krisis ketika memiliki anak yang menderita kanker (Greeff et al., 2014). Dalam menghadapi situasi tersebut, kompleksitas permasalahan yang secara kontinu dialami oleh orang tua dapat menimbulkan trauma dan krisis, tidak hanya secara fisik, namun juga secara psikis/psikologis, emosi, dan finansial (Gudmundsdottir et al., 2011).

Hasil penelitian ini menunjukkan bahwa terdapat hubungan stres pengasuhan dengan tingkat resiliensi orang tua anak penyandang kanker yang sedang menjalani perawatan dan pengobatan di RSUP DR Hasan Sadikin Bandung pada bulan November - Desember tahun 2018 dengan hasil $\mathrm{X}^{2}$ hitung $=32,4$ dan $p$-value sebesar 0,000 . Hasil penelitian ini sejalan dengan penelitian sebelumnya terkait resiliensi pada orang tua anak dengan kanker yang dilakukan oleh Ye et al. (2015) di China, bahwa stres yang 
dialami orang tua dalam merawat anak dengan kanker dapat berkembang menjadi patologis yang berdampak pada rendahnya resiliensi orang tua.

Dampak kanker anak terhadap psikologis orang tua menurut penelitian Dunn et al., 2012 menemukan bahwa orang tua anak penyandang kanker mengalami post-traumatic stress symptoms (PTSS) (71\%) yang ditandai dengan peningkatan tanda gejala depresi dan kecemasan. Gejala PTSS tersebut menurut penelitian lain, dilaporkan orang tua terjadi pada 2 hingga 4 minggu pertama setelah diagnosis kanker yang berupa gangguan stres akut pada ibu (51\%) dan ayah (40\%) (Kearney et al., 2015). Penelitian lain menyebutkan bahwa orang tua mengalami gejala kecemasan klinis (46\%), gejala depresi (27\%), mengalami disforia (47,3\%), serta distres psikologis $(50 \%)$ yang diantaranya berkembang menjadi patologis $(16 \%)$ yang muncul selama merawat anak dengan kanker (Bhattacharya et al., 2016; Neu et al., 2014; A. Rosenberg et al., 2014).

Stres dalam merawat anak dengan kanker terjadi akibat respons stres biopsikologis akibat dari diagnosis kanker anak terhadap kesejahteraan dan fungsi keluarga terutama orang tua yang dapat berakibat fatal tidak hanya pada orang tua, namun juga pada koping dan penyesuaian anak itu sendiri (Kearney et al., 2015; Noeker \& Petermann, 2015). Hasil penelitian ini juga didukung oleh penelitian yang dilakukan oleh (Rosenberg et al., 2014), dimana orang tua yang disebut resilien dalam merawat anak dengan kanker cenderung memiliki sumber personal yang tinggi dan distres psikologis yang rendah $(p=<0,001-0,01)$.

Stres merupakan faktor risiko dari resiliensi. Resiliensi keluarga merupakan proses dinamis antara faktor risiko dan faktor protektif. Faktor risiko merupakan faktor yang dapat mendorong munculnya outcome negatif dalam keluarga. Faktor risiko inilah yang harus diidentifikasi dan diatasi oleh keluarga untuk mencapai situasi yang dinamis dan memiliki kemampuan untuk bertahan dalam merawat anak dengan kanker.

Dalam mengidentifikasi faktor risiko tersebut, keluarga memerlukan bantuan baik dari anggota keluarga lain maupun profesional kesehatan (Fitryasari et al., 2018). Dalam meningkatkan resiliensi orang tua anak dengan kanker, diperlukan pengertian dalam berbagai faktor diantaranya adalah kesejahteraan emosional, perspektif individu, dan proses adaptasi individu itu sendiri ( $\mathrm{Li}$ et al., 2016).

Menurut Edraki \& Rambod (2018), orang tua yang menghadapi situasi dan kejadian yang traumatik menciptakan kondisi orang tua yang kesulitan dalam menciptakan personal defense sehingga meningkatkan stres yang terjadi yang berdampak negatif pada resiliensi yang terbentuk. Didukung oleh penelitian lain, yang menunjukkan bahwa resiliensi orang tua anak dengan kanker berkaitan dengan kesehatan mental seperti family coherence dan persepsi diri yang baik (Eilertsen et al., 2016).

\section{SIMPULAN DAN SARAN}

Berdasarkan analisis penelitian hubungan stres pengasuhan dengan resiliensi orang tua anak penyandang kanker dapat disimpulkan sebagai berikut:

1. Setengah responden orang tua anak penyandang kanker memiliki stres pengasuhan tinggi $(50 \%)$ dan setengah lainnya memiliki stres pengasuhan rendah (50\%), dengan nilai skor rata-rata 37,9 .

2. Sebagian besar $(55,5 \%)$ orang tua anak penyandang kanker memiliki tingkat resiliensi tinggi dengan nilai skor ratarata $>62,2$.

3. Ada hubungan stres pengasuhan dengan tingkat resiliensi orang tua 
anak penyandang kanker yang sedang mendapatkan perawatan dan pengobatan di RSUP Dr Hasan Sadikin Bandung pada bulan November - Desember tahun 2018.

Berdasarkan hasil penelitian dan simpulan penelitian, maka saran penelitian ini diantaranya adalah sebagai berikut:

1. Saran bagi Rumah Sakit

Saran bagi RSUP Dr Hasan Sadikin Bandung untuk dapat meningkatkan peran perawat sebagai konselor dengan mengadakan kelompok dukungan sosial (support group) yang dapat menjadi wadah bagi para orang tua untuk berbagi pengalaman, maupun sebagai edukator dalam memberikan informasi terkait perawatan anak dengan kanker yang dapat meningkatkan resiliensi orang tua dan menurunkan stres yang dirasakan oleh orang tua.

2. Saran bagi Orang Tua

Saran bagi orang tua untuk meningkatkan self-perception dan resiliensi dengan memanfaatkan informasi terkait perjalanan penyakit dan pengobatan, serta memanfaatkan dukungan sosial yang diterima baik dari keluarga, orang terdekat, petugas kesehatan, maupun teman untuk mengurangi stres yang diakibatkan oleh kondisi merawat anak dengan kanker.

3. Bagi Peneliti Lain

Saran bagi peneliti lain selanjutnya perlu mengidentifikasi faktor lain yang dapat berhubungan dengan resiliensi orang tua anak dengan kanker dengan lebih mendalam dengan menggunakan metode penelitian jangka panjang.

\section{DAFTAR PUSTAKA}

Badan Penelitian dan Pengembangan Kesehatan. (2013). Riset Kesehatan Dasar (RISKESDAS) 2013. Laporan Nasional 2013, 1-384. https://doi.org/1 Desember 2013

Bhattacharya, K., Pal, S., Acharyya, R., Dasgupta, G., Guha, P., \& Datta, A. (2016). Depression and Anxiety in Mothers of Children With Cancer and How They Cope With It: a Cross-Sectional Study in Eastern India. Asean Journal of Psychiatry, 17(1), 1-8.

Dunn, M. J., Rodriguez, E. M., Barnwell, A. S., Grossenbacher, J. C., Vannatta, K., Gerhardt, C. A., \& Compas, B. E. (2012). Posttraumatic stress symptoms in parents of children with cancer within six months of diagnosis. Health Psychology: Official Journal of the Division of Health Psychology, American Psychological Association, 31(2), 176-185. https://doi. org/10.1037/a0025545

Edraki, M., \& Rambod, M. (2018). Psychological Predictors of Resilience in Parents of Insulin-Dependent Children and Adolescents. International Journal of Community Based Nursing \& Midwifery, 6(3), 239-249.

Eilertsen, M.-E., Hjemdal, O., Le, T. T., Diseth, T. H., \& Reinfjell, T. (2016). Resilience factors play an important role in the mental health of parents when children survive acute lymphoblastic leukaemia. Acta Paediatrica, 105(1), e30-e34. https://doi.org/10.1111/apa.13232

Fitryasari, R., Yusuf, A., Nursalam, Tristiana, R. D., \& Nihayati, H. E. (2018). Family members' perspective of family Resilience's risk factors in taking care of schizophrenia patients. International Journal of Nursing Sciences, 5(3), 
255-261. https://doi.org/10.1016/j. ijnss.2018.06.002

Greeff, A. P., Vansteenwegen, A., \& Geldhof, A. (2014). Resilience in Families with a Child with Cancer. Pediatric Hematology and Oncology, 31(7), 670-679. https:// doi.org/10.3109/08880018.2014.905666

Gudmundsdottir, E., Schirren, M., \& Boman, K. K. (2011). Psychological resilience and long-term distress in Swedish and Icelandic parents' adjustment to childhood cancer. Acta Oncologica, 50(3), 373-380. https://doi.org/10.3109/ 0284186X.2010.489572

Habibpour, Z., Mahmoudi, H., Nir, M. S., \& Areshtanab, H. N. (2019). Resilience and its Predictors among the Parents of Children with Cancer: A DescriptiveCorrelational Study. Indian $J$ Palliat Care, Jan-Mar 25, 79-83. https://doi. org/: 10.4103/IJPC.IJPC_128_18

Kearney, J. A., Salley, C. G., \& Muriel, A. C. (2015). Standards of Psychosocial Care for Parents of Children with Cancer. Pediatr Blood Cancer, 62(5), S632-S683. https://doi.org/doi:10.1002/pbc.25761

Kohlsdorf, M., \& Costa, Á. L. J. (2012). Psychosocial Impact of Pediatric Cancer on Parents: A Literature Review. Paideia, 22(51), 119-129. https://doi.org/10.1590/ S0103-863X2012000100014

Li, X., Wu, Z., Liu, Y., \& Li, X. (2016). Resilience and Associated Factors among Mainland Chinese Women Newly Diagnosed with Breast Cancer. PLoS ONE, 11(12), 1-14. https://doi.org/10.1371/journal. pone. 0167976

Masa'Deh, R., Collier, J., Hall, C., \& Alhalaiqa, F. (2013). Predictors of Stress of Parents of a Child with Cancer: A Jordanian Perspective. Global Journal of Health Science, 5(6), 81-99. https://doi. org/10.5539/gjhs.v5n6p81

Masa'deh, R., \& Jarrah, S. (2017). Post Traumatic Stress Disorder in Parents of Children With Cancer in Jordan. Archives of Psychiatric Nursing, 31(1), 8-12. https:// doi.org/10.1016/j.apnu.2016.07.012

Muscara, F., McCarthy, M. C., Woolf, C., Hearps, S. J. C., Burke, K., \& Anderson, V. A. (2015). Early psychological reactions in parents of children with a life threatening illness within a pediatric hospital setting. European Psychiatry, 30(5), 555-561. https://doi.org/10.1016/j. eurpsy.2014.12.008

Neu, M., Matthews, E., King, N., Cook, P. F., \& Laudenslager, M. L. (2014). Anxiety, Depression, Stress, and Cortisol Levels in Mothers of Children Undergoing Maintenance Therapy for Childhood Acute Lymphoblastic Leukemia. JPediatr Oncol Nurs, 31(2), 104-113. https://doi. org/doi:10.1177/1043454213520346.

Noeker, M., \& Petermann, F. (2015). Childhood Cancer: Psychosocial Aspects. In International Encyclopedia of the Social \& Behavioral Sciences: Second Edition (Second Edi, Vol. 3). Elsevier. https:// doi.org/10.1016/B978-0-08-0970868.14066-8

Norberg, A. L., \& Boman, K. K. (2008). Parent distress in childhood cancer: A comparative evaluation of posttraumatic stress symptoms, depression and anxiety. Acta Oncologica, 47(2), 267-274. https:// doi.org/10.1080/02841860701558773

Parker, K., \& Hall, M. A. (2017). Childhood Cancers: Diagnostic Considerations. The Journal for Nurse Practitioners, 13(8), e401-e402. https://doi.org/10.1016/j. nurpra.2017.05.017

Rosenberg, A. R., Starks, H., \& Jones, B. (2014). "I know it when I see it." The complexities 
of measuring resilience among parents of children with cancer. Supportive Care in Cancer, 22(10), 2661-2668. https://doi. org/10.1007/s00520-014-2249-5

Rosenberg, A., Wolfe, J., Syrjala, K., Yi-Frazier, J., Curtis, J. R., \& Baker, S. (2014). The Impact of Personal Resilience Resources on Psychosocial Outcomes in Parents of Children with Cancer (SA509-C). Journal of Pain and Symptom Management, 47(2), 451-452. https://doi.org/10.1016/j. jpainsymman.2013.12.205

Ye, Z. J., Guan, H. J., Wu, L. H., Xiao, M. Y.,
Luo, D. M., \& Quan, X. M. (2015). Resilience and Psychosocial Function Among Mainland Chinese Parents of Children With Cancer. Cancer Nursing, 38(6), 466-474. https://doi.org/10.1097/ NCC. 0000000000000220

Ye, Z. J., Qiu, H. Z., Li, P. F., Liang, M. Z., Wang, S. N., \& Quan, X. M. (2017). Resilience model for parents of children with cancer in mainland China-An exploratory study. European Journal of Oncology Nursing, 27, 9-16. https://doi.org/10.1016/j. ejon.2017.01.002 